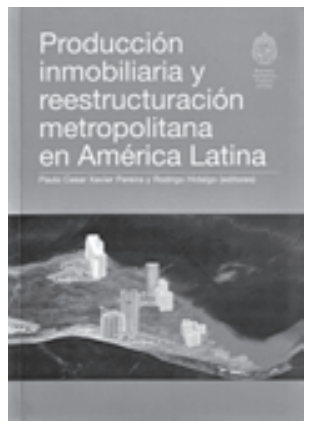

\title{
Paulo Cesar Xavier Pereira y Rodrigo Hidalgo (Editores). Producción inmobiliaria y reestructuración metropolitana en América Latina
}

\author{
Santiago: Instituto de Geografía, Pontificia \\ Universidad Católica de Chile, Serie GeoLibros No 11 \\ - Facultad de Arquitectura y Urbanismo de la \\ Universidad de São Paulo, 2008, 347 p.
}

José Rosas Vera ${ }^{1}$

La obra citada corresponde a una iniciativa que ha permitido que el Instituto de Geografía de la Pontificia Universidad Católica de Chile y la Facultad de Arquitectura y Urbanismo de la Universidad de São Paulo Ileven adelante esta alianza de investigación, convocando en esta coedición a un selecto grupo de estudiosos de la realidad urbana y regional latinoamericana, para abordar, a través de diferentes flancos problemáticos las transformaciones que vienen acaeciendo en las metrópolis de nuestro continente y de las consecuencias que -según palabras de sus editores- "ha provocado en ellas la reconversión económica, las transformaciones del rol del Estado, las modificaciones de la estructura social y los cambios territoriales asociados"(Pereira e Hidalgo, 2008).

El tema tratado se inserta en la profunda mutación dentro del curso de la modernización. En efecto, se trata de la emergencia de nuevos rostros en la fábrica urbana, convergencia de varios hechos en que diversos autores coinciden, a saber: una nueva base económica metropolitana, políticas de desregulación y liberalización, facilidades de gestión para el crecimiento y expansión urbana, movilidad espacial, segregación social, concentración de servicios, signos de capitalidad asociada a las redes globales financieras, proyectos infraestructurales y ar-

\footnotetext{
1 Arquitecto. Decano Facultad de Arquitectura, Diseño y Estudios Urbanos UC (Chile). E-mail: jrosasv@uc.cl
}

quitectónicos emblemáticos, etc., y que confirman a las ciudades capitales como el territorio de oportunidades para la especulación urbana.

En este contexto, resulta fundamental, de mantenerse las actuales características antes indicadas, por una parte, saber cómo y sobre qué operaciones cristalizan los intereses y aspiraciones de los agentes que producen, dan forma al espacio urbano y configuran la economía material de una ciudad, así como, por otra parte, entender las responsabilidades que le son pertinentes a la administración y gestión pública urbana, y la función que asumimos los profesionales de la arquitectura y el urbanismo frente al ordenamiento, regulación y mediación de las dificultades que el fenómeno de la metrópoli registra.

Ello es aún más relevante cuando sabemos que nos encontramos frente a un hecho donde cerca de tres cuartos de la población mundial reside en aglomeraciones y regiones urbanas, y donde la mitad de dicha población vive en territorios periféricos, que son sectores altamente vulnerables, con débiles equipamientos, servicios públicos y escasa vinculación a la organización urbana general, por no decir excluidos totalmente de esta.

A mi juicio, no se puede entender las operaciones urbanas futuras de reequilibrio e inclusión política, social y espacial que requieren las actuales metrópolis -cuya forma 
en gran parte es consecuencia de un urbanismo de promotores-, si no comprendemos esta metamorfosis, tanto en lo que se refiere a los sectores vinculados a los negocios y a la modernidad requerida por la globalización, como en aquellos lugares sin modernización y fragmentados del resto de la metrópoli.

Como lo indica Capel (2002), "el paisaje se convirtió en un objeto de estudio esencial de la geografía desde principios del siglo $X X$, en parte para asegurar la identidad de la disciplina frente a las amenazas de división entre la geografía física y la geografía humana. La combinación de fenómenos en la superficie terrestre se traduciría en diferentes tipos de paisaje, de morfologías territoriales". Y es que al decir de Capel, es "misión del geógrafo", junto a otras disciplinas espaciales, la observación y reinterpretación de las huellas y marcas que reflejan la morfología urbana y descubrir las expectativas de transformación que cada espacio construido sugiere.

Para la Arquitectura, la preocupación por el abordaje de los estudios espaciales y morfológicos de las ciudades y el territorio en que estas organizaciones encajan, constituye no solo uno de los motivos centrales, sino que, en el marco de producción inmobiliaria y reestructuración metropolitana que este texto nos presenta, resultaría difícil eludir la responsabilidad disciplinar y profesional que nos es pertinente.

Según De Mattos, una de las causas explicativas de la acentuación de la mercantilización del desarrollo urbano sería consecuencia de "la imposición de un enfoque de gestión pública sustentado por criterios de neutralidad y subsidiariedad, que ha contribuido, por una parte a consolidar condiciones mucho más favorables a los negocios inmobiliarios $y$, por otra parte, a otorgar mucho mayor autonomía y libertad que las que habían tenido hasta ahora, a las decisiones y acciones de las empresas y de las familias en todo lo relativo a bienes raíces" (De Mattos, 2008: 24). En este proceso, junto con confirmarse un urbanismo de los negocios inmobiliarios, se manifiesta una pérdida de importancia del sector público en la toma de decisiones y administración urbana, y una creciente debilidad de las estructuras políticas locales por fragmentación municipal de una organización metropolitana que crece y se expande en el territorio.

Entender, por tanto, la especificidad que en la actualidad tiene la configuración de un territorio con organizaciones metropolitanas de esta naturaleza, significa poder revelar las características de este proceso y visualizar las oportunidades, desafíos y derroteros que tal especificidad contiene.

Como señalan los editores, el libro está organizado en cinco secciones y dieciocho capítulos. Sinópticamente, un primer apartado denominado Globalización y Producción inmobiliaria: ¿la emergencia de una nueva ciudad?, con textos de De Mattos, Lencioni y Xavier Pereira; un segundo apartado Ilamado Movilidad Espacial y Reestructuración Metropolitana: Lectura de los procesos recientes, con textos de Ortiz y Escolano, Cerda Troncoso y Moreno Pérez; un tercer apartado titulado Exclusión y desigualdad en la producción inmobiliaria, con textos de Riwilis, Vidal Koppmann; Hidalgo, Borsdorf y Zunino; Gomes de Mendoça y Teixera de Andrade; y Rodríguez y Méndez; un cuarto apartado denominado El Estado, la vivienda social y sus consecuencias en la geografía social metropolitana, con textos de Lacerda, Morim Melo y Normando Barros Filho; Nobre, Teixera de Campos y Lima Ferreira y Rofé; y finalmente un quinto apartado intitulado Centros Históricos y Espacios Metropolitanos de Servicios, con textos de Cantú Chapa, Motoda y Buthuhy, Spolon García.

Cabe señalar, aunque no ha sido declarado por los editores, que no es posible una panorámica como la presentada sin un hilo argumental e ideológico que las vincule, y en ello el papel de Xavier Pereira e Hidalgo, que nos introducen a las temáticas diversas, resulta crucial. De este modo se nos permite distinguir, además de una serie de conceptos e ideas al respecto y una desagregación analítica para entender fenómeno, las diferentes modalidades e instrumentos que constituyen el amplio espectro de prácticas inmobiliarias que forman parte de la construcción de la ciudad contemporánea tanto en el nivel estatal como en el privado y comunitario. 
En ese sentido, podríamos afirmar que las posibilidades operativas que se deducen de los diagnósticos que entregan los diferentes apartados de esta publicación, están en directa relación con la comprensión profunda del problema. Como lo indican los editores, "el estudio de los efectos de la producción inmobiliaria en la ciudad, entendida como el modo en que los diferentes agentes que participan directa o indirectamente en la generación de suelo urbano, es uno de los desafíos que siguen presente para explicar la forma en que se configuran en la actualidad las metrópolis latinoamericanas" (Pereira e Hidalgo, 2008: 7).

De este modo, entender las complejidades y metamorfosis de los asentamientos metropolitanos en el momento actual, a partir de la acumulación de inversiones realizadas en la fábrica urbana y en la construcción de los espacios públicos, como consecuencia de las significativas transformaciones que la organización socioespacial manifiesta bajo el impulso de la modernización capitalista registradas en el último cuarto de siglo XX, se hace un imperativo, al analizar cómo operan en la ciudad, que se transforma a pasos agigantados ante nuestros ojos, los diversos agentes sociales, políticos y económicos. Desde un punto de vista disciplinar, estas investigaciones son de un gran valor al momento de intentar cualquier práctica profesional orientada a revertir los excesos y compensar los desequilibrios que se registran. De una forma gruesa podría decirse que ello es en parte un desafío propuesto por los editores, ya que entender la producción inmobiliaria de la ciudad desde distintos flancos temáticos y sugerir unos campos de acción como un proyecto colectivo, exige una nueva disposición frente a las evidencias y la participación de un amplio espectro social, político y económico, donde todos debemos salir ganando.

En efecto, como muchos de los autores en este trabajo lo confirman, las ciudades latinoamericanas a partir de los ochenta y noventa evidencian cambios estructurales en la política económica nacional, la que junto con propiciar la liberalización de esta y la desregulación del Estado en asuntos urbanos que incidirán de manera profunda en el territorio del país -específicamente en la base económica metropolitana- manifestarán la aparición progresiva de intervenciones urbanas que implicaron considerables recursos financieros y transformaciones físicas en el paisaje urbano y regional, sobre todo en la dimensión arquitectónica y en la descomposición del suelo en ciertas localizaciones.

Es de todos sabido las consecuencias que ha tenido en la morfología urbana y tipologías edificatorias esta nueva cultura urbanística asociada a la arquitectura bajo las nuevas tecnologías y estrategias publicitarias de mercado, donde las edificaciones asociadas a la operación inmobiliaria son piezas fundamentales de la imagen metropolitana.

Incluso estas intervenciones, muchas de ellas caracterizados como megaemprendimientos privados fundamentados en unas directrices de política pública y de acciones de gobierno sobre la ciudad y sociedad entendidas como artefactos de promoción y publicidad, son sin lugar a duda la concreción de un modelo político urbano de enormes consecuencias en la construcción del espacio público y privado y explicativos de la profunda mutación metropolitana.

Según De Mattos, "la adopción de los criterios de subsidiariedad estatal y el consecuente repliegue de la intervención pública en la gestión urbana ha sido otro factor que contribuyó a otorgar un mayor protagonismo a los negocios inmobiliarios en los procesos de transformación urbana" (De Mattos, 2008: 29). De hecho, el desplazamiento de una planificación centralizada tradicional-cuyos errores nadie defiende- a una dominada por la dimensión mercantil del territorio metropolitano -que es ineficiente-, centrada en ciertos sectores de esta, introducirá unos cambios no menores en la organización espacial.

Se trata no solo de la incorporación de capitales privados a la renovación y desarrollos urbanos, cuestión que desde antes existía, sino de un modelo en que el Estado decide renunciar al control y supervisión de las actuaciones del sector privado, más bien promocionándolos, aduciendo la imperiosa 
necesidad de mecanismos más flexibles de participación y la emergencia de una idea de ciudad regida por la lógica de los negocios y el manejo de esta a partir de una "imagen líder" y una serie de "proyectos anclas".

Como queda confirmado en el argumento central de este libro, el tipo de ciudad resultante es cada vez más un conjunto fragmentario de ciudades y un mosaico de lugares emblemáticos de la globalización que se localizan en específicos lugares de la organización general, que vienen a sumarse a los procesos de transformación registrados por expansión periférica, viviendas subvencionadas, infraestructuras concesionadas y otros artefactos urbanos colocados en unas geografías difusas.

De este modo, las grandes líneas que dan forma a la ciudad podrían ser entendidas como un campo de tensiones entre el papel protagónico que tiene la iniciativa privada y el mercado, y el rol subsidiario de la actividad de planificación. De allí que los principales cambios en las organizaciones urbanas, tal como lo señalan desde distintos tópicos los autores que reúne este libro, son cambios en las formas de la estructura urbana que se manifiestan en fragmentación social y espacial, desarrollo de nuevas centralidades, la aparición de nuevos barrios populares, condominios cerrados y consumo protegido desarrollado bajo la forma de malls, shopping centers y centros comerciales, edificaciones corporativas, nuevos enclaves, y grandes despliegues de infraestructuras viarias y nuevos servicios urbanos.

La metrópoli en el contexto de globalización alcanza pues una mayor expansión territorial como ciudad región, compuesta ahora de una diversidad de piezas y ciudades menores $y$, en consecuencia, una extensión de las infraestructuras viarias y de servicios, produciendo a la vez una incorporación cuantitativa de nuevos suelos para la propia organización urbana que los requiere para estas nuevas demandas.

De este modo, la relación entre la ciudad y el territorio dará lugar a lo que se ha denominado, en la literatura reciente, la "ciudad difusa", a saber: ciudad donde las tradicionales fronteras entre la organización urbana y el medio rural, o entre centro y periferia tienden a desaparecer, posibilitando así un territorio mixto, híbrido, indefinido, sin límites entre el campo y la ciudad, y donde definitivamente el espacio urbano no solo ha perdido la coherencia entre las partes y el todo, sino que evidencia una exacerbada fragmentación y autonomía de sus componentes, evidenciando además escasas relaciones con la organización espacial general, salvo las conexiones viales.

En este marco de reestructuración espacial no caben dudas del enorme rol que han jugado las infraestructuras viarias. Según Rodríguez y Méndez "la reducción de distancias que ha introducido la revolución de la velocidad del tiempo con su fulminante disminución provoca formas de ocupación del suelo difusas que involucran mucho territorio y nuevas formas de consumirlo" (Rodríguez y Méndez, 2008: 212).

Es más, las propias infraestructuras viarias evidencian unas lógicas de desarrollos de nuevos programas asociados a los desplazamientos, en que, como señala Hidalgo, se dan fuera de la conurbación del área metropolitana. Y no me refiero a los conjuntos habitacionales que provee el Estado, que en este contexto de políticas públicas emergen desprovistos de cualquier equipamiento, ni los evidentes nuevos centros comerciales, sino a los servicios derivados de la propia lógica de la movilidad que se adscriben a la lógica de las autopistas, como son los nuevos usos de suelo que registran los terrenos inmediatos al paso de estas vías. De este modo, han emergido nuevos programas, entre los cuales podemos señalar: parques temáticos, parques industriales y tecnológicos, clubes privados, centros de ventas tipo oulet, complejos de cines y servicios de entretenimiento, equipamientos hoteleros y turísticos, centros empresariales, estaciones de servicio, hipermercados, centros nocturnos de diversión, moteles, restaurantes y ciudades privadas, entre otros.

Estas nuevas formas que asume el crecimiento periférico de baja densidad de las ciudades es además de operaciones de renta basadas en la gestión del suelo de escaso valor económico o productivo, una clara y 
fácil búsqueda de rentabilidades por parte del capital financiero a través de una actividad inmobiliaria de bajo coste $y$, por lo general, de dudosa calidad. El denominador común es la firme intención de construir la ciudad de manera rápida, donde la responsabilidad profesional por una mejor ciudad parece relegada a solo el cumplimento de unas pocas exigencias en cuanto a calidad del espacio urbanizado.

En efecto, la hegemonía financieroinmobiliaria que se concretiza, por una parte en una diversidad de actuaciones puntuales y desagregadas en una cada vez más extensa aglomeración metropolitana y regional que amplía las área residenciales, así como por otra, en megaemprendimientos no siempre periféricos, que impactan en tejidos urbanos consolidados y en centros y barrios históricos, impone unas lógicas y dinámicas de proyecto que nos exige no solo su comprensión y entendimiento, sino perfila la imperiosa necesidad de explorar nuevas actuaciones urbanísticas que represtigien a la calidad de vida y sustentabilidad de estos asentamientos como horizonte, al mismo tiempo que articulen el negocio inmobiliario en un objetivo concordante con una buena y digna ciudad.

En este horizonte, el trabajo de Xavier Pereira e Hidalgo se muestra, además de revelador de la compleja situación urbana que tenemos, auspicioso. De hecho, las distintas miradas que nos han entregado el conjunto de autores en este texto, desagregadas en diferentes apartados y escalas del fenómeno, constituyen una cuidadosa aproximación analítica que se vuelven imprescindibles para proyectar nuestras futuras actuaciones. Es que, coincidiendo con los editores, estamos enfrentados a un diálogo entre investigadores, profesionales y académicos de distintas disciplinas, interesados -al decir de Manuel de Solá Morales i Rubió- por el estudio minucioso y detallado de la ciudad, que es, aparte de necesario, urgente.

\section{Referencias bibliográficas}

HIDAlGO, R. y PEREIRA, P. Producción inmobiliaria y reestructuración metropolitana en América Latina. Santiago de Chile: Instituto de Geografía UC, Serie GeoLibros No 11 - Universidad de São Paulo, 2008.

CAPEL, H. La morfología de las ciudades. Sociedad, cultura y paisaje urbano. Barcelona: Colección Las Estrella Polar 37. Ediciones del Serbal, 2002, Vol. 1.

DE MATTOS, C. Globalización, negocios inmobiliarios y mercantilización del desarrollo urbano. En: HIDALGO, R. y PEREIRA, P. Producción inmobiliaria y reestructuración metropolitana en América Latina. Santiago de Chile: Instituto de Geografía UC, Serie GeoLibros No 11 - Universidad de São Paulo, 2008.

RODRÍGUEZ, I. y MÉNDEZ, E. Paisajes y arquitecturas de las nuevas tendencias inmobiliarias fronterizas: el caso de Tijuana. HIDALGO, R. y PEREIRA, P. Producción inmobiliaria y reestructuración metropolitana en América Latina. Santiago de Chile: Instituto de Geografía UC, Serie GeoLibros № 11 - Universidad de São Paulo, 2008. 